\title{
A Study on Economic Development of the Hui Nationality in Ningxia under the "The Belt and Road Initiative" Strategic System
}

\author{
Gu Jijian \\ Chongqing Communications Vocational College, Jiangjin, Chongqing 402247
}

\begin{abstract}
The development of Hui nationality property economy in Ningxia is based on the new institutional economy from the theoretical perspective, and it is found that it is regulated by ethnic groups and habits and so on. The development of its property right economy has been greatly affected, which can not adapt to the development of modern market economy. Therefore, this paper proposes to completely change the status of the property rights of Hui nationality by reforming the economic behavior and consciousness in religious beliefs, increasing the degree of economic openness, expanding the special education of market economy and clarifying the property right system.
\end{abstract}

\section{INTRODUCTION}

The long-standing business tradition and outstanding business endowment of the Hui nationality have been recognized by the world for thousands of years. Since ancient times, the Hui people have mostly made a living through business, and the wealthy merchants of the Hui people in the Yuan Dynasty have become important ethnic groups affecting society, politics, and economy. But in the Ming Dynasty, the economic development of the Hui nationality is closely combined with the customary characteristics of the Hui nationality, that is, the business model, property right system, and economic growth mode of the Hui nationality continue to be the traditional model, and even more, the property right economy under the customary laws and regulations of the nationality have been consolidated. This kind of property right economy gradually merge with the Islamic culture. This special blending of culture and business has formed a major feature of the Hui nationality property right economy. Usually, their business behavior is strictly influenced and dominated by the Islamic culture and classic provisions. Abiding by the Islamic etiquette and living customs, the pattern of the Hui family-style property right economy has limited the Hui economy's integration with the modern economic trend, and has seriously restricted the Hui economy's development to a new height of the modern market economy.

\section{A brief introduction to the economic literature of the Hui nationality}

At present, there is not a highly relevant article under the topic of "Ningxia property right economy". However, in the study of Ningxia economy, some articles about Ningxia property right economy can be found. Scholars have studied the property right economy of the Hui nationality in Ningxia from different perspectives. Zhang Yan(2008) explored the impact and constraints on the local economic development from some backwardness of the Hui culture, but did not analyze the root of the problem by digging deeper and theoretically ascending to the perspective of the property right system. Shi Chengze(2017) demonstrated the possibility and goodness of the economic development of the Hui nationality in Ningxia from the aspects of innovation-driven, economic growth structure driven transformation, optimization of factor structure, improvement of total factor productivity, optimization of industrial structure, and increase of effective supply, but neither find that the property right economy of the Hui nationality is the fundamental constraint on economic development, nor solve this fundamental problem. Wang Linling(2017) advocated seizing the opportunity of "The Belt and Road Initiative", relying on inter-regional open cooperation, undertaking industrial transfer, building an outward-oriented industrial system and an open platform, strengthening the endogenous driving force of Ningxia's economic development, and building a more open inland economy at a higher level. However, what are the current obstacles to open economy? National customs and behaviors have not given a clear answer to how to regulate the open economy. This should be the first problem under consideration. Lu Minrong(2016) believes that to study the modern economic development of the Hui nationality, it is necessary to carry out an in-depth analysis of the cultural traditions of the agriculture and commerce, adhere to the positive ideas and attitudes of the cultural traditions of the agriculture and commerce, retain the customs and characteristics of national economy, and insist traditional business ethics in order to achieve a diversified, characteristic and harmonious development. But traditional commercial ethics is precisely the reason for the formation of the Hui ethnic property right economy. Only by finding the cause, using it, transforming it, and developing it can

E-mail: gumuran2006@126.com 
effectively promote the development of the Hui ethnic property right economy. According to the current trend, if the Hui's property right economy is to develop in a healthy and rapid manner, I am afraid it is an air tower. Jin Xiaofang (2015) believes that the "Longshan Model" is the academic summary and affirmation of the successful experience of Hui's fur intermediary trade in Longshan Town, Zhangjiachuan. She clearly expresses that the "Longshan Model" gradually disintegrated in the process of market transformation. The reason is mainly due to the establishment of external markets and the dependence on traditional paths. In particular, the dependence on traditional paths has seriously hurt the development of the Hui economy. Because the property right system formed by its traditional path has solidified its property right economy, this economic system is rigid, limited, and family matured. Du Huajun(2013) demonstrated that many rural towns still retain strong traditional economic components. These components are both the characteristics and highlights of the property right economy of the Hui nationality in Ningxia, and they are obstacles to their development, especially how to adapt to the development of the modern market economy. Wang Ping(2013) believes that the economic structure model of "doing business in the place of residence" in traditional cities and towns of the Hui society actually impedes the economic property right structure of the tribe. The community is not just a geography residential unit but a social and cultural life unit, and it is a business unit based on the basic needs of the community and the regional economic cycle system. The social structure of the community which is surrounded by temples is not a normal open property right structure. In other words, it does not fully meet the needs of the development of modern market economy.

\section{The basic situation of the economic benefits of the Hui nationality in Ningxia}

For more than 1,000 years before the reform and opening up, the Hui nationality is a minority in China with a relatively high level of business and the ability to do business. After the reform and opening up, it was completely out of date. According to the level of disposable income of Ningxia residents in 2014, namely 15,906 yuan, there is a gap of $1 / 3$ of that of the Inner Mongolia residents, namely 20,559 yuan. If the disposable income of the Hui residents is taken out, the per capita income will not be higher than 12,000 yuan, and the per capita disposable income of the well-performing Mumin New Village is only 9,000 yuan - It ranges from more than 26,000 yuan (research statistics), and the average disposable income of residents is about 18,000 yuan, and the income of other Hui people is not optimistic (see the figure below)1).

[1] Lei Xiaowu. A Brief Analysis of the Comparison and Trend of Farmers' Income Growth in Ningxia [j]. China Statistics, No.8, 2015, $\mathrm{p} 22$.

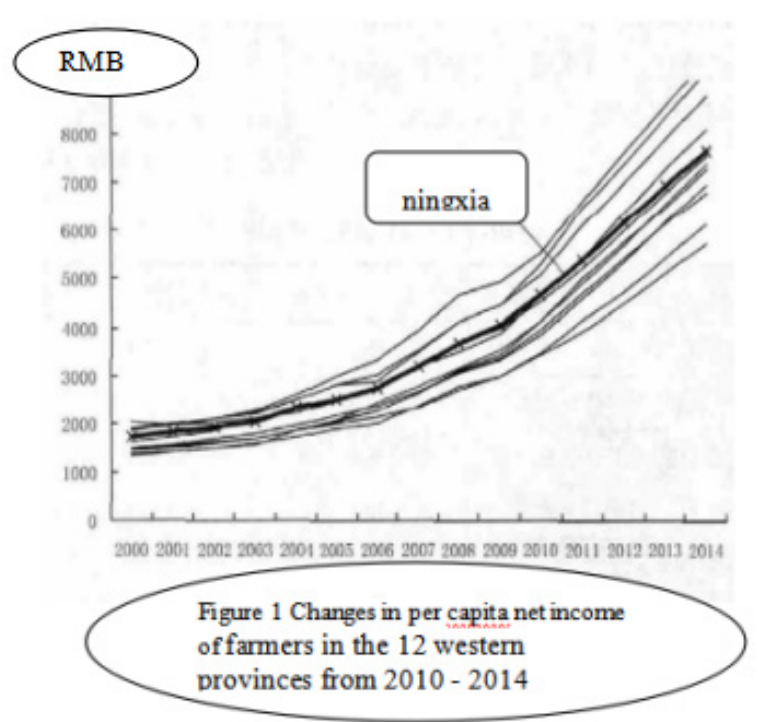

According to the survey, (1)the more remote the Hui ethnic agglomeration areas are, the worse their economic activities are. (2)The more concentrated agglomeration areas are, the lower their level of economic development is, even in areas with convenient transportation or significant location advantages. (3) The "Matthew Effect" easily turns the Hui economy into a depression, and a series of issues such as ethnic conflicts and social security will follow, and it will also make it difficult to maintain stability and achieve a well-off society.

\section{The causes of the "slump" of the Hui economy}

The root cause of the economic slump of the Hui nationality lies in the solidification of the "nationality" of the ethnic property right system, which has caused it fail to meet the needs of the development of China's mainstream property right system. The mainstream property right system uses the market economy as a hub for resource allocation and the use, disposal, transfer, and income are carried out in accordance with market rules, and the resource allocation is priced by the market. However, the Hui property right system clearly has ethnic characteristics, and the definition of goods is not commercialized in accordance with market transaction principles. It is customary to define articles instead of mainstream property rights in accordance with national laws, which largely violates economic laws and regulations on property rights. The reasons are as follows:

1. Religious beliefs affect the marketization of the property right system. Adhering to the customary law of the Hui nationality "fixes" the property right economy and is disconnected from the mainstream market property right system. The right to deal with property rights is left to male parents and the daughter does not enjoy the property rights, which is virtually limited the scope of economic activities. The prohibition of interest has restricted the growth of its commodity awareness, but the practice of arbitration by Imam on the settlement of property right disputes has violated the laws of the market and the fundamentals of the property right system in many cases. Unless Imam is a modern economist (also 
can be consciously cultivated), the Hui people's awareness of property rights will be seriously restricted and the cultivation of their economic vitality will be hindered. "Zakat must be given to the poor and cannot be applied to the purchase of religious property and collective things, building mosques, opening schools, business profits, gifts, etc. Zakat items which are paid by Muslims also include gold and silver, jewelry, goods, agricultural products, camels, cattle and sheep, etc. The stipulated payment rate is $2.5 \%$. Commodities and goods are paid in equivalent to cash, and agricultural products are taxed at $5 \%$ and $10 \%$ according to the conditions of land irrigation. The tax of mineral is $20 \%$; camels, cattle, and sheep each have its own specific regulation"2. This is the root cause of the economic downturn of the Hui nationality.

2. Low economic openness restricts economic vitality. The first one is the economic openness: for more than 1000 years, the Hui's economic activities have been concentrated in agriculture, forestry, animal husbandry, fisheries, and wholesale and retail industries. Capital has the second lowest degree of openness, and engineering and labor services have the lowest openness among the five provinces and are "0" in many years, which fundamentally restricts economic vitality in Ningxia. The current opening rate in Ningxia contributes only $24.44 \%$ to economic development which is 20.12 percentage points lower than the national average rate $(44.56 \%)$. Among the scores and rankings of 31 provinces (autonomous regions and municipalities) in the mainland of China, Ningxia is also only in front of Guizhou, Qinghai, and Tibet, ranking in the fourth from bottom ${ }^{3}$.

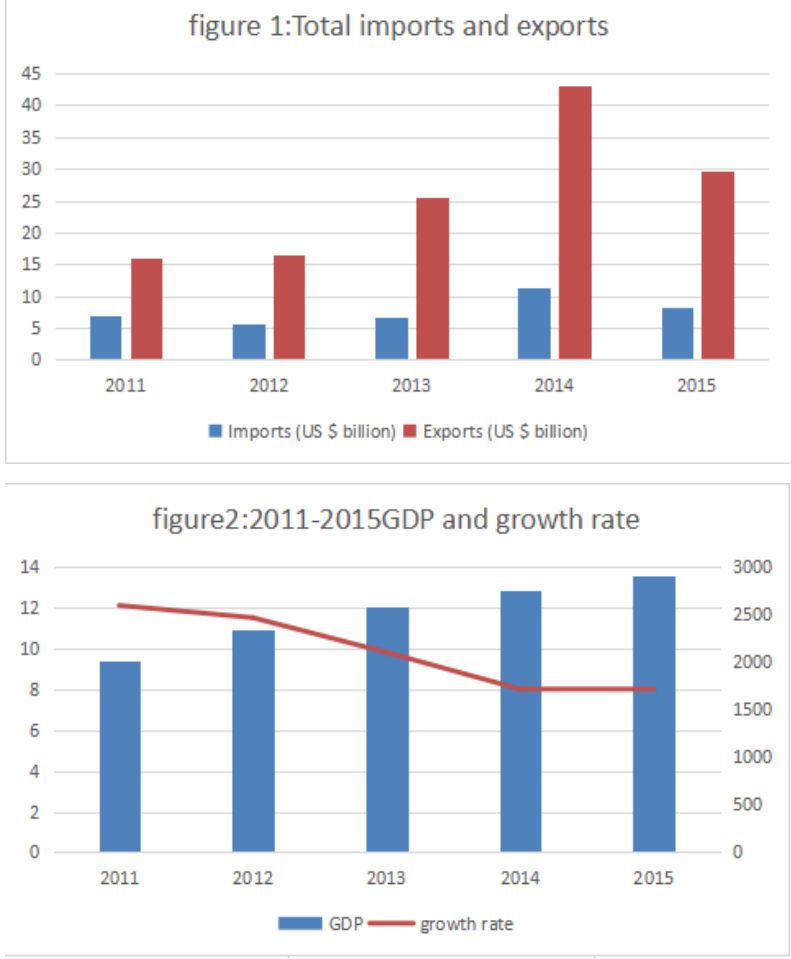

[2] Liu Ye. Interpretation of the Quran [m]. Hohhot: Inner Mongolia People's Publishing House, 2004. p103.

[3] Li Shuping. Drawing a blueprint for Ningxia's opening to the outside world [N]. Ningxia Daily, 2013-08-21.
Note: The statistics of the pictures are from the Autonomous Region Statistics Bureau of the Hui nationality in Ningxia in 2015

3. The lack of education in the market economy has led to a lack of economic awareness. From 1982 to the present, the statistical yearbook found that the Hui nationality is one of the ethnic minorities with the slowest increase in the average number of education years. The lack of education will definitely lead to the lack of modern economic awareness of the Hui people. The non-professional market economy education (continuing education) is difficult to fundamentally impact the original and narrow religious economic consciousness of the Hui people, and the pace of derailment from the modern market economy is increasing. 
Table 1 The Number of Education Enrollment, Undergraduates and Graduates in 2015

\begin{tabular}{|l|l|l|l|l|}
\hline \multicolumn{1}{|c|}{ Category } & \multicolumn{1}{|c|}{$\begin{array}{c}\text { The Number of } \\
\text { Schools }\end{array}$} & $\begin{array}{c}\text { The } \\
\text { Number of } \\
\text { Education } \\
\text { Enrollment }\end{array}$ & \multicolumn{1}{|c|}{$\begin{array}{c}\text { The Number of } \\
\text { Undergraduates }\end{array}$} & \multicolumn{1}{|c|}{$\begin{array}{c}\text { The Number of } \\
\text { Graduates }\end{array}$} \\
\hline General Higher Education & 18 & 34699 & 119410 & 29654 \\
\hline Postgraduate & - & 1703 & 4403 & 1410 \\
\hline Adult Higher School & 1 & 11439 & 29172 & 11607 \\
\hline $\begin{array}{l}\text { Secondary Vocational } \\
\text { Education School }\end{array}$ & 31 & 30832 & 82117 & 25942 \\
\hline Ordinary Middle School & 299 & 144447 & 433996 & 144253 \\
\hline $\begin{array}{l}\text { Ordinary Elementary } \\
\text { School }\end{array}$ & 1693 & 94170 & 583509 & 96199 \\
\hline Kindergarten & 788 & 79900 & 192892 & 83913 \\
\hline Special Education School & 12 & 188 & 3900 & 352 \\
\hline
\end{tabular}

Note: The statistics of the pictures are from the Autonomous Region Statistics Bureau of the Hui nationality in Ningxia in 2015

4. The property right system unreasonably regulates the growth space of economic activities. The prohibition of normal borrowing interest, the daughter-in-law's inability to enjoy the right to inherit property, the transaction of goods in accordance with Islamic law, the ban on the sale of some animal meat and tobacco and alcohol are all based on the Qur'an property right system which is defined to engage in economic activities. The historical nature of the Qur'an has caused the current property right system of the Hui people to be far from meeting the needs of the development of a modern market economy, thereby preventing the growth space of the Hui economic activities and causing its poverty.

\section{A bunch of suggestions to improve the economic performance of the Hui nationality}

1. Renovate economic behaviors and consciousness in religious beliefs. The innovation of beliefs is the slowest and most effective. But it is the most difficult to deal with the most likely to cause contradictions. It requires finding an opportunity or event, such as a large-scale and vicious event brought about by economic disputes that are judged by the Hui customs to forcibly reform some of the religious beliefs that hinder economic development and do not conform to the development of the property right system (It can be learned from some Xinjiang Uyghur practices). It can be accepted by the people within a period of time. The gift giving of 300-1000 yuan each time in Mumin Xincun's sentiments effectively impacts the economic behavior and consciousness of its original religious beliefs. It obviously has market economic characteristics and can be viewed by default or by the same ethnic group. On this basis, the Hui people are further guided to dock with the property right system required by the market economy, effectively integrate into the market, enhance market awareness and vitality, and expand the space for economic activities.

2. Increase economic openness. There are three main measures to increase economic openness:(1)Strengthen the exchanges between the Hui people and other ethnic groups, including internal exchanges between the Hui people, and between the Hui people and economically developed nations, especially the Han people. Measures include visits, mutual visits, demonstrations, long-term technology transfer, etc. which can be considerably increased. The economic openness of the Hui nationality is performed subtly for a long time. (2) Economic opening is to expand the scope of business within the priority scope of economic activities of the Hui nationality. It cannot be limited to the agriculture, forestry, animal husbandry, fisheries, and wholesale and retail industries. A narrow economic activity area means that the economic openness is low. At the same time, the Hui capital is encouraged to generate interest within the legal scope, and expand the areas in which capital participates in operations, including financing activities and production activities of capital among other ethnic groups. (3)To expand the mixed ethnic groups in the Hui ethnic cluster area, special attention should be paid to the introduction of people from areas with more developed market economic activities to preferentially enter the area to engage in economic activities. Various economic thoughts will strongly impact the relatively closed economic space of the Hui nationality, and naturally will increase the economic openness of the Hui nationality.

3. Strongly expand special education for the market economy. Provinces where ethnic minorities gather have not yet launched a special education model for the process of marketization of the minority economy. There are four ways that can be implemented without violating ethnic religion: (1)Promote the return of the Han people who have gone back home as a model for transplanting market economy education, promote modern market economic behavior in rural areas in different ways, and use the behavior to educate the Hui people, such as supporting their entrepreneurial innovations, business training courses, and economic conscious special education of migrant workers, etc. Successful cases have a point-and-face effect. (2)A large number of the Han people participate in the economic awareness education. To an acceptable level, the Han people who have been relatively successful in the Hui ethnic gathering area are brought together to actively guide the Hui people's economic activities by talking, pulling home, etc., and the Han people and the Hui people realize a group 
carrying out activities in the twinning sub-method of one to subsidize related personnel. (3)The Hui people under the age of 45 need to receive modern economic education in indefinite forms such as continuous educations in classrooms and regular lectures, etc. to promote effective guidance for the Hui people. When there are demands, there must be immediate cases emerging. (4) Activities of economists going to the countryside and organizing economists across the country to conduct market economic education activities at appropriate opportunities, especially personally guiding related innovations and entrepreneurship activities. If you can save several and bring them back to life, you will be able to do more with less effort.

4. Clarification of the property right system. Repack and develop the form of the property right system of Mumin New Village, and reform its unreasonable places as a model and solidify the system, which is in line with the property right consciousness and mainstream property rights of the Hui people. The system is docked and evaluated on the basis of trials in designated areas. If it can effectively promote the economic development of the Hui nationality, it will be used as a model to promote the Hui ethnic agglomeration area, or forced change, or induced change. If the effect is not achieved, consult again, find the problem, and continue to improve until it reaches an acceptable range, and then promote it. To be precise, the right to own, control, exchange and benefit of property rights is clearly defined. Capital can generate interest, business can be diversified, and a part of it can be rich first. Otherwise, it falls into a poverty trap as a whole.

\section{CONCLUSION}

In a word, it is very difficult for the property right economy of the Hui nationality in Ningxia to make a fundamental breakthrough in the case of relatively closed or no external force to change it. However, the implementation of the "the Belt and Road Initiative" strategy can fundamentally reverse this pattern, because this strategy system can penetrate all corners of the Hui nationality's property right economy, from changing people to changing the property right system, and then essentially changing the connotation of the property right economy, breaking the original property right economic behaviors, and realizing a new structural economic reorganization of the property right economy.

* This is a static comparison and dynamic change research group of seven ethnic minority property right systems under the "the Belt and Road Initiative" strategy of the National Social Science Fund (2015XJL001) (No .: ZDB2018036) and the phased results of the Research on the Fusion Path of the Intersection of the Three Strategies of the Chongqing Excellent Youth Project.

\section{ACKNOWLEDGMENT}

First of all, I would like to express my gratitude to all those who helped me during the writing of this thesis. I gratefully acknowledge the help of my supervisor, who has offered me valuable suggestions in the academic studies. In the preparation of this thesis, she has spent much time reading through each draft and provided me with inspiring advice. Without her patient instruction, insightful criticism and expert guidance, the completion of this thesis would not have been possible.

Secondly, I also owe a special debt of gratitude to all the professors in Foreign Languages Institute, from whose devoted teaching and enlightening lectures I have benefited a lot and academically prepared for the thesis.

Lastly, I should finally like to express my gratitude to my beloved parents who have always been helping me out of difficulties and supporting without a word of complaint.

\section{ABOUT THE AUTHOR}

Gu Jijian (1980.8-) male, Han, Shandong, Ph.D., professor of Chongqing Jiaotong Vocational College, master tutor, mainly engaged in higher education and cultural industry research

Phone: 158261500058

E-mail: gumuran2006@126.com

Mailing address: No. 555 Scientific Research Office, Xiangfu Avenue, Shuangfu Street, Jiangjin District, Chongqing

Zip code: 402247

\section{REFERENCE}

1. Lei Xiaowu. A Brief Analysis of the Comparison and Trend of Farmers' Income Growth in Ningxia [j]. China Statistics, No.8, 2015, p22.

2. Liu Ye. Interpretation of the Quran [m]. Hohhot: Inner Mongolia People's Publishing House, 2004. p103.

3. Li Shuping. Draw a blueprint for Ningxia 's opening to the outside world [N]. Ningxia Daily 2013-08-21. 